\title{
Reform and Exploration of Basic Education Model in Service Areas of Normal Colleges and Universities
}

\author{
Bing Wang \\ School of Preschool and Elementary Education \\ Shenyang Normal University \\ Shenyang, Liaoning 110034, China
}

\author{
Liyan Guo* \\ School of Preschool and Elementary Education \\ Shenyang Normal University \\ Shenyang, Liaoning 110034, China
}

\author{
Sai Bi \\ School of Preschool and Elementary Education \\ Shenyang Normal University \\ Shenyang, Liaoning 110034, China
}

\begin{abstract}
Based on the perspective of serving basic education in normal colleges and universities, aiming at strengthening the reform and development of basic education, and based on years of work experience, this study constructs three modes of "postpractice replacement training", "three-party linkage regional promotion" and "internal and external nesting double teacher training". This model plays a leading role in serving basic education in normal universities, and also provides a strong reference for the government's reform and exploration of regionalized education.
\end{abstract}

Keywords-Normal Colleges and Universities; Serving Regional Basic Education; Model; Reform; Exploration

\section{INTRODUCTION}

In order to strengthen the reform and development of basic education, we should aim at serving basic education in an allround way and cultivating high-quality and professional primary school teachers. Relying on the disciplinary advantages of Teacher Education in teachers' colleges and universities, taking the new round of teacher training in basic education curriculum reform as an opportunity, following the basic principles of cooperation and co-construction among universities, local governments, primary and secondary schools, with the same objectives, shared responsibilities, shared interests and coordinated development, we jointly explore and expand new modes and ways of basic education reform and development, comprehensively improve the level and quality of basic education, improve the quality of teachers, and promote regional basic education reform and development services.

\section{Training Mode OF "SPECIFIC-JOB TRAINING AND REPLACEMENT TRAINING” FOR MUTUAL BENEFIT}

"Specific-job training and replacement training" is an effective training mode of reciprocity, mutual benefit, cohesion, complementarity and win-win between pre-service

Project Source: This paper is the result of the phased research of the "13th Five-Year Plan” (2017) “Cultural Literacy Curriculum Integration Model and Evaluation System Regional Research” (Project No. JG17CB383). education for normal students and post-service continuing education for rural teachers, and also an important way to serve local basic education. [1]In the Opinion of the Ministry of Education on Promoting the Work of Teachers' Internship in Teachers' Colleges (No. 4, 2007), it is clearly pointed out that it is of great significance to carry out the practice in teachers' colleges and to link teachers' colleges with primary and secondary schools. The "specific-job training" model is a reform and innovation of educational practice and teacher training, and has a win-win effect on the integration of teacher education, the training of higher education talents and the balanced development of basic education.[2]

\section{A. Specific-job Training: Prospective Teacher Training Model}

In the seventh semester, the fourth grade normal students (prospective teachers) are assigned to the practice base of education for a period of 10 weeks to replace the special-job training of primary and secondary school teachers in the practice base. Excellent primary and secondary school frontline teachers in practice bases, as interns' instructors, become "tutors" to help and guide normal students to complete the 10week fixed-post internship task. At the same time, the firstline teachers of primary and secondary schools in the replaced practice base will be invited to colleges and universities to enjoy "academic holidays" and complete the relevant content of teacher training. Teachers' students who take on postpractice completely replace the work of primary and secondary school teachers. They are managed by referring to the duties of full-time primary and secondary school teachers in practice bases. The purpose is to enable these prospective teachers to apply theoretical knowledge to teaching practice in a relatively short period of time, so that they can grasp the clear professional consciousness, firm professional belief, deep professional emotion, excellent professional ethics, excellent professional skills of primary and secondary school teachers in educational practice, and enhance the awareness of 
serving rural education through paired tutoring and on-the-job internship of excellent instructors.

\section{B. Replacement Training: Training Model for On-the-job Teachers in Rural Areas}

The rural teachers replaced by Specific-job training came to normal universities and were organized by Teachers' Professional Development College. They provide trainees with comfortable accommodation, a "one-card" on campus, and a "tailor-made" course meal. In addition, they have formed a team of experts consisting of excellent teachers in the whole country, provincial top teachers, provincial famous teachers in teaching, school leaders in various disciplines, well-known teachers and researchers in provincial basic teaching and research centers, and outstanding backbones in primary and secondary schools, and use various forms such as centralized teaching, school-based follow-up training and group counseling to train rural teachers in curriculum concepts, teaching methods and technology applications. High-quality school observation, on-site interaction, thematic discussion, micro-video, lesson evaluation, self-diagnosis, expert review, peer review, key and difficult points analysis, expert workshops, interactive days with famous teachers, and "hand in hand" with famous teachers of provincial and municipal schools have been adopted to introduce teaching experience to undergraduates. They also make full use of the rich library resources, electronic network and educational application technology "small stove" to make up for the favorable conditions, quickly supplement the energy, absorb the "frontier", broaden their horizons, and improve professional quality. Teachers in schools also help them to get rid of their homesickness and leaving their posts. They often give them psychological counseling and teach them the methods and techniques of psychological health education.

\section{III. "THREE-WAy LiNKAGE AND REgIONAL ADVANCEMENT" CoOperative Mode of Mutual Benefit SHARING}

"Three-way linkage and regional advancement" service basic education alliance is a mutually beneficial and shared education alliance with the development of regional basic education as the main body, which is led by teachers' colleges, participated by local governments and cooperated by primary and secondary schools. It is a synergistic innovation model built by three parties to promote the development of regional basic education. For many years, Shenyang Normal University has established Specific-job training, replacement training and education practice base like "Rural Basic Education Service Zone", "Rural Basic Education Service Special Zone", "Rural Basic Education Regional Collaboration", "Teacher Professional Development Mobile Station" and "Teacher Professional Development School" respectively for the underdeveloped areas of western, northern, eastern, southern and middle Liaoning provinces, covering more than 50 schools in urban and rural areas and more than 10 cooperative units such as district and county education bureaus. In the process of implementing the "specific-job training and replacement training", we gradually sum up experience, drawing lessons, adjusting plans and improving them have promoted the reform of quasi-teacher training mode in normal universities, improved the quality and level of rural basic education, and built a comprehensive, three-dimensional and high-level platform for training, training, communication and interaction of "double teachers".

\section{A. Government-led and Team Collaboration Model}

The government attaches great importance to high-level driving, overall planning, scientific layout, policy guidance, vigorous promotion and co-development, which are the guarantee for the effective implementation of the cooperative school-running model. Through the unified leadership of the Municipal Committee, the Municipal Government and the administrative department of education, the formulation of programs, top-level design, building the framework, establishing rules and regulations, promoting plans, follow-up guidance and other operational modes, classified implementation, gathering advantages, scientifically setting up cooperative teams, taking high-quality schools as the leader, setting up educational cooperative teams covering basic education segments, and giving full play to the radiation and driving role of team's high-quality resources, the collaborative teams focus on the linkages in research and training, interoperability in management, synchronization in quality tracking, and co-construction of school culture, so as to unify teaching, cooperate in teaching and research, promote the common development of member schools with team quality schools, improve the overall level of running schools, and achieve the goal of balanced and high-quality development of regional basic education.

\section{B. Linkage Model of Famous Schools Leading Urban Areas}

In order to enhance the radiation effect of high-quality resources in the basic education stage and promote the balanced development of Regional Compulsory education, the educational administrative departments should take the lead of famous schools, link up towns and towns in urban areas, link up strength and weakness, link up primary schools and cooperate inside and outside the city. Leading schools implement demonstration guidance, concentrate on teaching and research, online joint training and other ways to promote the radiation of high-quality resources, promote the cooperative development of member schools, fully demonstrate the effect of leading schools, high-quality leadership, demonstration of famous teachers, team sharing, urban linkage, cooperative development, symbiosis and winwin. Collaborative schools implement inter-school teacher assignment, management promotion, teaching linkage, moral education interaction, network training interconnection, open lesson demonstration, partner exchange, examination linkage and team linkage. It realizes the cooperation of educational resources, teaching and research, and information technology networking among cooperative schools, enlarging the effect of high-quality resources, pooling the advantages of development, aligning with foreign famous schools, absorbing and transplanting the experience of famous schools, broadening the cause of running schools, enhancing the strength of running schools, constantly narrowing the gap between schools, achieving the goal of full coverage of high-quality resources, and co-development of cooperative teams, and realizing the urban-rural linkage model of basic education. 


\section{University Leadership and Regional Promotion Model}

We should adhere to the responsibility and mission of Local Normal Universities in facing basic education, serving basic education, guiding basic education, sticking to the downward focus, promoting the construction and development of basic education, and constructing a new mode of promoting regional cooperation of basic education and accelerating the reform and development of basic education. We should set up "Teacher Professional Development School" or "Teacher Professional Development Mobile Station" in the regional collaboration of basic education, carry out counterpart support, send education to the countryside, send education to school and set up, order and orientated collaborative services, start the "Excellent Teacher Training Project" and carry out such special activities as "Expert Workshop", "Professor's Research Room", "Open Day for Famous Teachers", "Principal's Forum" and "Academic Salon" and launching the "tailormade" course meal through collation, organizing activities such as "on-site observation", "teaching reflection", "diagnostic evaluation", "itinerant speech", "thematic discussion" and "dialogue between famous teachers",etc. to achieve all-round, three-dimensional and high-level teacher exchanges and interaction, promote the upgrading of teachers' professional competence, and effectively promote the upgrading of regional basic education level.

\section{Teachers' Professional DeVelopment Mode of "INTERNAL AND EXTERNAL NEST BUILDING AND DOUBLE TEACHERS TRAINING"}

It is necessary to reform the discipline-based teaching in normal universities, the inefficiency of practical teaching, the inadequacy of Vocational adaptability, the lack of professional stamina of primary and secondary school teachers, the unbalanced development of urban and rural teachers, and the lack of guidance. At the same time, we should create a "tutorial system" with compatible disciplines, complementary advantages and double-hiring and double-guiding, so that prospective teachers can learn theoretical knowledge in school, cultivate practical skills outside school, build nests inside and outside school, and accept the "double-teacher" training.

\section{A. Constructing "Double-employment" and "Win-win" Tutorial System}

"Dual tutorial system" is a cooperative construction between Shenyang Normal University and local education administration departments, primary and secondary schools, which has established a stable, standardized and long-term cooperative teacher education practice base and formed a team of tutors in the form of mutual employment of tutors between universities and primary and secondary schools. Teachertraining students are provided with experienced researchers and excellent teachers in primary and secondary schools to guide their professional quality, teaching skills, educational and practical links, moral education and employment. [3] University professors, subject experts, teaching researchers and key teachers are employed to provide professional guidance for primary and secondary school teachers. Over the past few years, under the guidance of practical instructors, normal school students have accumulated teaching and practical experience through dialogue with famous teachers, principals' forums, participation in teaching and research activities such as "teacher workshops", "parents' open days", "theme class meetings" and practical activities such as "job training" and "post suspension" in primary and secondary schools. Through the construction of interaction mechanism between universities and primary and secondary schools, the "Teacher Professional Development Model" of Coconstruction and cooperation between universities and primary and secondary schools is established, so as to make the teaching and discipline construction of teachers' profession in line with the curriculum reform and teaching practice of primary and secondary schools. The "double-employment" tutorial system achieves a win-win effect of mutual employment, mutual assistance, reciprocity and mutual benefit in teaching practice.

\section{B. Construct a Long-term Mechanism of Co-construction and Cooperation between "Internal and External Nests"}

Shenyang Normal University has established a stable cooperative relationship with 150 primary and secondary schools and kindergartens in Liaoning Province and established a teacher education practice base. The two sides have carried out subject cooperation, school-based research and training, and accepted the "three practices" of normal students. Senior experts, professors and excellent principals of primary and secondary schools are invited, and the backbone of disciplines is organized into a "tutorial group". Academic lectures, trainees' training and technical guidance are conducted regularly or irregularly every year. Through the establishment of "double-teacher" training platform inside and outside the school, carrying out various forms of research activities, such as teacher workshops, famous teachers' studios, project collaboration groups, and carrying out the "mutual assistance within the group" model, which is incorporated into the theoretical tutors, off-campus tutors and normal students in Colleges and universities. By using the method of "multiteacher, multi-guide" and observing closely according to the scale, the theoretical literacy and teaching ability of prospective teachers can be improved rapidly. To carry out the "teacher-apprentice pairing" mode, that is, senior teachers and prospective teachers "pairing" to help guide and interact, so as to rapidly enhance their experience, is also an important measure to achieve the goal of modern apprenticeship personnel training [4]. The mode of "education-oriented" is that senior experts from disciplines enter the classroom, guide and guide, diagnose, extract experience, and promote the teaching ability of prospective teachers to improve significantly. The model of "leading by famous teachers" guides the professional growth of prospective teachers, promotes efficient classroom teaching research, optimizes classroom structure, explores the optimization of teaching process efficiency, and continuously improves the quality of education and teaching [5]. The "self-perfection" mode guides prospective teachers to actively participate in the topics of both in-school and out-of-school tutors, forms research directions, condenses ideas, accumulates experience and produces results in research. This close cooperation mode of "double teachers" training and "nesting inside and outside" cultivates excellent human resources for the development of 
urban and rural education, and builds an excellent team with noble teacher ethics, excellent professional quality, innovative spirit and broad vision, so as to promote the overall quality of teachers in the whole city and enhance regional education quality [6].

\section{CONCLUSION}

Through the constructing of "specific-job training and replacement training" for mutual benefit training mode, "three-way linkage and regional advancement" cooperative mode and teachers' professional development mode of "internal and external nest building and double teachers training", higher normal education and basic education are closely integrated, realizing the reform, innovation and indepth exploration of the basic education mode in the service area of normal universities.

\section{REFERENCES}

[1] Bao Bengang, Cheng Zhikai. Reflections and Explorations of Specificjob Training in Normal Undergraduate Colleges in Transition Period- Taking Hunan Institute of Science and Technology as an Example. Education Modernization. 2018.07

[2] Huang Saiqi. Some Thoughts on the Model of "Specific-job Replacement”. Journal of Luoyang Normal University.2017.05

[3] Huang Linqing, Qiu Jiangting. Research on the role of professional postgraduate tutors. University Education.2019.04

[4] Zhao Hongjun, Lu Ming. Research and Practice on the Construction of Modern Apprenticeship Dual Tutor Team. Education and Teaching Forum.2019.04

[5] Guo Hongwei. Master's Studio Leads the Division to Generate Long. Middle School Curriculum Resources. 2019.04

[6] Wang Canming, Guo Zhiming. Leading the professional development of teachers to improve the quality of regional education. Basic Education Reference. 2018.10 